\title{
Presumed paradoxical embolus in a patient with diabetic ketoacidosis
}

This article was published in the following Dove Press journal:

International Journal of General Medicine

18 September 2015

Number of times this article has been viewed

\section{Catherine Langevin \\ Caroline Lamarche \\ Robert Z Bell \\ Michel Vallée}

Department of Nephrology, Maisonneuve-Rosement Hospital, Montreal, QC, Canada
Correspondence: Michel Vallée Department of Nephrology, Maisonneuve-Rosement Hospital, 5415 Assomption Boulevard, Montreal, QC, HIT 2 M4 Canada

$\mathrm{Tel}+\mathrm{I} 5 \mathrm{I} 22523489$

Fax + I 5 I4 2553026

Email mvallee.hmr@ssss.gouv.qc.ca
Abstract: Thrombotic complications figure among the most frequent causes of mortality in diabetic ketoacidosis (DKA) and hyperosmolar state. We report the case of a 55-year-old woman presenting with DKA whereby a newly discovered patent foramen ovale was found due in part to the observation of bilateral deep vein thrombosis in legs, bilateral multiple pulmonary embolisms, and left subclavian acute artery thrombosis. Diabetes is known as a hypercoagulability state, and DKA is rising as a risk factor for vascular events. The importance of prophylactic anticoagulation should be emphasized in this setting.

Keywords: thrombosis, hypercoagulability, prophylactic anticoagulation, pulmonary embolism

\section{Case presentation}

A 55-year-old nonsmoking unmedicated black woman without past surgical or medical history apart from mild untreated hypertension presented with deteriorated general condition, lethargy, and confusion. There was no personal or family history of thrombosis. A few weeks prior to admission, she had polyuria, polydipsia, and polyphagia. Laboratory findings mainly showed diabetic ketoacidosis (DKA) in the context of a new-onset diabetes with a $\mathrm{pH}$ of 7.22, partial pressure of carbon dioxide $\left(p \mathrm{CO}_{2}\right) 12 \mathrm{mmHg}$, bicarbonates $5 \mathrm{mmol} / \mathrm{L}$, random glucose $56.8 \mathrm{mmol} / \mathrm{L}$, urinary ketones $7.8 \mathrm{mmol} / \mathrm{L}$, sodium $158 \mathrm{mmol} / \mathrm{L}$, chloride $111 \mathrm{mmol} / \mathrm{L}$, potassium $7.9 \mathrm{mmol} / \mathrm{L}$, urea $24.0 \mathrm{mmol} / \mathrm{L}$, creatinine $302 \mu \mathrm{mol} / \mathrm{L}$, international normalized ratio (INR) 1.16, partial thromboplastin time $25.5 \mathrm{~s}$, and fibrinogen $5.92 \mathrm{~g} / \mathrm{L}$. The calculated osmolarity of 396.8 mOsm and intensity of the hyperglycemia evoked mixed features of hyperglycemic hyperosmolar state (HHS). A DKA protocol composed of intravenous insulin and normal saline fluid was started, and the latter rapidly changed to a quarter-normal saline and then dextrose $5 \%$ in water due to initial hypernatremia. Cerebral computed tomography scan showed no intracranial hemorrhage or other acute problems. No thromboprophylaxis was given. One of the two blood cultures returned positive for Gram-positive cocci in clusters 29.8 hours after admission for which vancomycin was started. Institutional Review Board approval as well as informed, written consent was not deemed necessary for the following retrospective review. All principles outlined in the Declaration of Helsinki were followed.

A peripherally inserted central catheter (PICC) line was installed on the left side on day 3 to facilitate fluid administration. The patient's level of consciousness improved, as she was no longer confused. With regard to thromboprophylaxis, compression stockings were preferred to heparin because of thrombocytopenia (platelets at $199 \times 10^{9} / \mathrm{L}$ 
at arrival to 49 on day 4) with a normal coagulogram. Thrombotic thrombocytopenic purpura was contemplated, but no schistocyte was seen that day or on the two subsequent blood films. On day 4, the INR was slightly elevated at 1.33 (prothrombin time of $16.2 \mathrm{~s}$ ) with a normal activated partial thromboplastin time of $27.5 \mathrm{~s}$, a marginally low fibrinogen of $1.98 \mathrm{~g} / \mathrm{L}$, elevated D-dimers at $>2 \mathrm{mg} / \mathrm{L}$, and lactate dehydrogenase (LDH) of $334 \mathrm{U} / \mathrm{L}$, revealing some extent of disseminated intravascular coagulation. On day 5 , those values were stable, and the patient reported mild catheterrelated discomfort that was relieved by acetaminophen. On day 6, platelet count was at $29 \times 10^{9} / \mathrm{L}$ and $\mathrm{LDH}$ was $848 \mathrm{U} / \mathrm{L}$, and the patient was found to have dyspnea and tachypnea without chest pain, and left arm pain from shoulder to wrist as well as erythema without induration or edema. The patient had a blood pressure of $115 / 81 \mathrm{mmHg}$, heart rate $104 / \mathrm{min}$, oxygen saturation $97 \%$, respiratory rate $40 / \mathrm{min}$, and temperature $36.7^{\circ} \mathrm{C}$. On the left arm, no exudate was seen at the PICC line site. Radial pulse was nearly absent, and capillary refill was prolonged. There was hand numbness and motor function impairment from the elbow to the distal hand extremity. Arterial thrombosis and pulmonary emboli were suspected.

The vascular surgery team was contacted, and the patient immediately underwent a Doppler ultrasonography and angioscan which showed bilateral deep vein thrombosis (DVT) in legs, bilateral multiple pulmonary embolisms, and left subclavian artery thrombosis with significant extension in descending aorta. The concomitant events raised suspicions of paradoxical embolus through a patent foramen ovale (PFO). There was no evidence of cerebral involvement. A left subclavian thrombectomy was performed. The venous aspect of the clot clinically heightened the probability of a PFO. This was confirmed by transesophageal echocardiography (TOE) which showed left-to-right and spontaneous right-to-left shunts through a PFO but no thrombus. Unfractionated heparin was given as treatment for pulmonary embolisms as the patient was hemodynamically stable. Platelet transfusions were given as platelets count reached $25 \times 10^{9} / \mathrm{L}$. Bacteria in the previously positive blood culture was identified as Micrococcus sp., a commensal organism considered nonpathogenic, so vancomycin was discontinued. Over 2 days, creatine kinase went from a high of $25,367 \mathrm{U} / \mathrm{L}$ to $6,331 \mathrm{U} / \mathrm{L}$. Factor $\mathrm{V}$ (506) Leiden mutation and prothrombin 20210A mutation were ruled out. At discharge, the patient had regained most of her left arm's motricity and had scheduled physiotherapy appointments. Warfarin bridging was done using tinzaparin until therapeutic INRs of 2-3 were reached. Long-term possibly lifelong - anticoagulation was discussed, while PFO closure was not promoted.

\section{Discussion}

Diabetes is known as a hypercoagulability state, making it a risk factor for stroke and heart disease, mainly because of endothelial abnormalities, coagulation activation, hypofibrinolysis, and chronic platelet hyperactivity. ${ }^{1}$ Acute hyperglycemia is believed to boost coagulation by its positive impact on factor VII and factor VIII activity as well as on tissue factor pathway inhibitor levels. Hyperinsulinemia also contributes as it increases plasminogen-activator inhibitor type 1 level, a substance isolated in disproportionate quantity in atheromatous material extracted from diabetic patients. ${ }^{1}$

Moreover, thrombotic complications, for example, myocardial infarctions, thrombosis, and disseminated intravascular coagulation, are among the most frequent causes of mortality in DKA. ${ }^{2}$ As a consequence, DKA is rising as a possible risk factor for vascular event, although no large study is currently available.

The prothrombotic state in DKA could be explained by paradoxical platelet behavior, ${ }^{3,4}$ coagulation, ${ }^{3-5}$ endothelium activation, ${ }^{6}$ and diminution of the anticoagulation system. ${ }^{6-9}$ Treatment could normalize protein $\mathrm{C}$ activity and von Willebrand factor concentration. ${ }^{6}$ Global activation of the fibrinolytic system is also present in DKA. Altogether, these studies imply that diabetes is a hypercoagulability state and that DKA generates further hemostatic abnormalities (Table 1).

Is it probable that coagulation abnormalities related to DKA translate into vascular events? In a population-based

Table I Hematological parameters during diabetic ketoacidosis and after treatment

\begin{tabular}{llll}
\hline Marker & $\begin{array}{l}\text { At } \\
\text { diagnosis }\end{array}$ & $\begin{array}{l}\text { Variation at } \\
\text { 96-I20 hours from } \\
\text { the initial value }\end{array}$ & Reference \\
\hline vWF activity & $\uparrow$ & Toward normalization & 6 \\
Homocysteine & $\downarrow$ & Normalized & 6 \\
Protein C activity & $\downarrow$ & Normalized & 6 \\
Protein C & - & Increased & 5 \\
Protein S & $\downarrow$ & Stable & 6 \\
Folate & $\uparrow$ & Toward normalization & 6 \\
Fibrinogen & Normal & Stable & 6 \\
Factor VIII & $\uparrow$ & Toward normalization & 5 \\
Platelets & $\uparrow$ & Toward normalization & 5 \\
White blood cells & $\uparrow$ & Normalized & 5 \\
PT & - & Decreased & 5 \\
PTT & - & Increased & 5 \\
\hline Abbreviations: & & vWF & 5 \\
\hline
\end{tabular}

Abbreviations: vWF, von Willebrand factor; PT, prothrombin time; PTT, partial thromboplastin time; $\uparrow$, augmented; $\downarrow$, diminished. 
case-control study, neither diabetes nor its complications (retinopathy, nephropathy, neuropathy, DKA) were considered as independent risk factors for DVT when controlling for nursing home confinement and hospitalization for major surgery or acute medical illness. ${ }^{10}$ However, this study was not powerful enough to demonstrate a difference in DKA patients. An association was made by Keenan et al between uncomplicated diabetes, DKA or HHS, and in-hospital DVT or readmission for DVT in the subsequent 3 months. ${ }^{11}$ Compared to patients with diabetes without complications, patients with DKA were not found to be at higher risk, while the HHS group did (hazard ratio =3.0). ${ }^{11}$ It has been hypothesized that this difference is due to some risk factors of thrombosis as dehydration, hyperosmolarity, and hyperglycemia being possibly more pronounced in HHS. Therefore, although we know that DKA modifies coagulation dynamics, experimental design does not allow the identification of a direct link between DKA and vascular events. What about the risk of DVT associated with central venous catheter (CVC)? Two retrospective pediatric studies found an increase in the incidence of CVC-associated DVT in DKA patients., ${ }^{7,12}$

At the moment, DVT prophylaxis is not officially indicated as part of the management protocol of DKA, although some care centers have implemented DVT prophylaxis in DKA with signs of HHS. ${ }^{13} \mathrm{HHS}$ is recognized as a risk factor for DVT, and the Oxford Handbook of Clinical Medicine of 2014 advises using DVT thromboprophylaxis in case of hyperosmolar nonketotic diabetic coma, while it only mentions thrombosis as a complication of DKA without recommending prevention. ${ }^{14,15}$ As we previously saw, even with aggressive hydration, the hypercoagulability state persisted until resolution of DKA and sometimes after. Some cases of thrombosis in DKA occurred in patients receiving prophylactic anticoagulation, but it is thought that it can at least lower the risk in a context of accumulating cases of vascular events in DKA, for example, pulmonary embolism as initial presentation or within 72 hours. ${ }^{16-18}$ In this context, we agree that our relatively healthy patient would have benefited from DVT prophylaxis at arrival due to her DKA and complete immobility for 6 days. Anyhow, the HHS traits identified could have been stated as an indication for prophylaxis as there is evidence that this condition increases the risk of thrombosis, adding to our patient's burden at arrival. It should also be emphasized that asymptomatic thrombocytopenia was a strong red flag of the platelet consumption due to the underlying developing thrombosis. It is thought that the patient developed her DVTs in the context of the DKA, which then traveled directly to the lungs, and via the

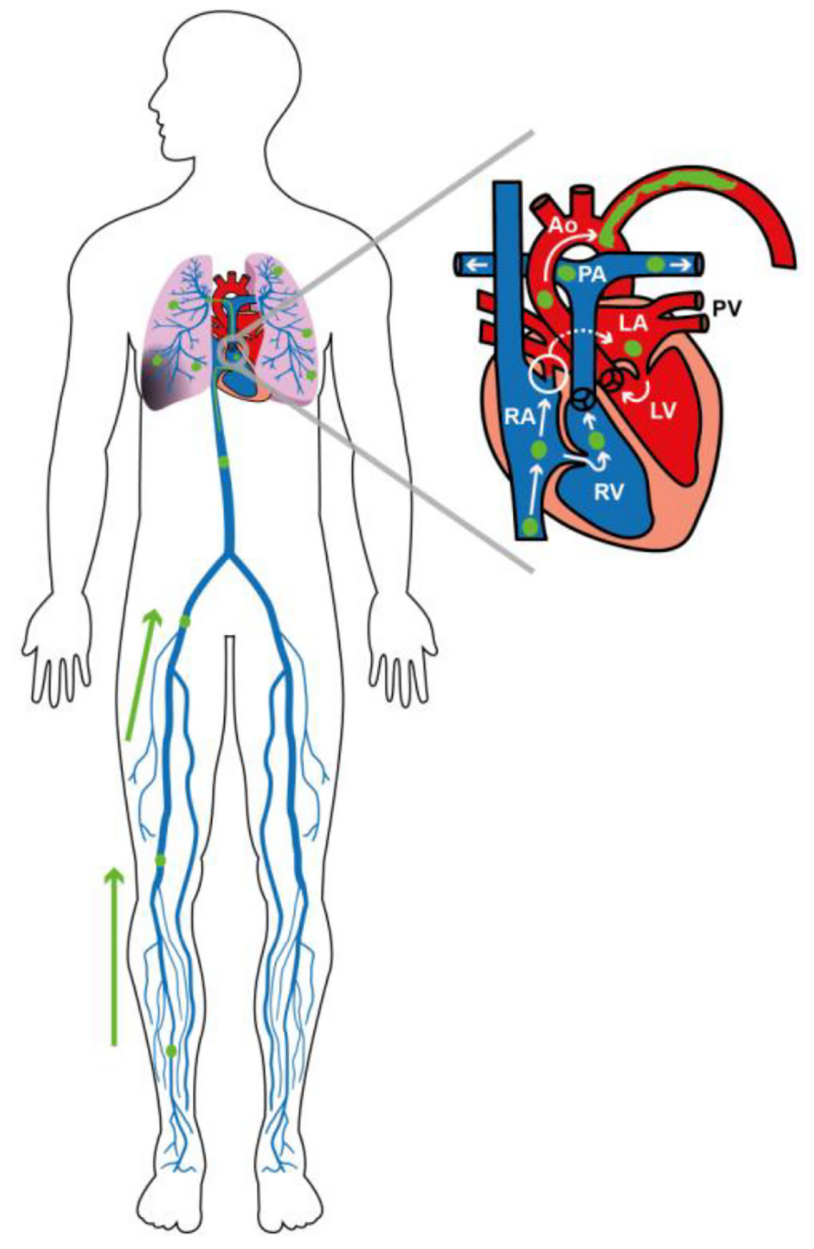

Figure I Schematic representation of deep venous thromboembolisms in the legs, bilateral pulmonary embolisms, and a paradoxical embolus in the left subclavian artery through a patent foramen ovale.

Abbreviations: Ao, aorta; PA, pulmonary artery; PV, pulmonary vein; LA, left atrium; LV, left ventricle; RA, right atrium; RV, right ventricle.

PFO, to the left arm (Figure 1). It might be argued that this supplementary thrombosis was part of a "thrombotic crisis" as venous and arterial thromboses are being studied as a continuous spectrum. ${ }^{19}$ In situ arterial thrombosis surely remains a reasonable explanation to acknowledge and could be precipitated by DKA with mixed HHS features. However, the sudden onset in a previously asymptomatic patient and the proximity in timing with the venous thrombosis oriented us in another direction.

Suspicion for PFO was raised by the context of concomitant venous and arterial thrombosis and by the venous aspect of the clot noted during the thrombectomy. This visual constatation was based on the macroscopic particularities described between an arterial thrombus and a venous thrombus due to their composition differences. The first is usually depicted as a firm and white material made of platelets and fibrin, while the latter tends to be spongy with ill-defined layers of red 
material rich in erythrocytes, which is what was seen in this case. ${ }^{20,21}$ No histopathological examination of the thrombus was done, but it might be interesting to compare the clinical classification with the images of the angioscan as this technique appears to give satisfactory results for estimating the proportion of erythrocytes in a thrombus. ${ }^{22}$ Thus, the combination of DVTs, pulmonary emboli, acute arterial thrombosis containing what was said to be a venous thrombus, and a PFO with a spontaneous right-to-left shunt certainly qualifies as a presumptive case of paradoxical embolus, while a definitive diagnosis would have required a thrombus to be seen during TOE. Medical treatment was chosen over surgical management as the added benefit to PFO closure remained unclear in this case. Studies about secondary prevention of embolic events among patients with PFO did not offer convincing evidence, although they mainly addressed cryptogenic stroke instead of peripheral thromboembolism. ${ }^{23-25}$

\section{Conclusion}

Recognizing the possible link between DKA and thromboembolism should prompt high suspicion for thrombosis, especially in a context of thrombocytopenia. It should raise awareness about the importance of prophylactic anticoagulation, since pulmonary embolism is a serious condition and approximately $25 \%$ of people have a PFO, making it possible for paradoxical embolism to happen as seen in this case of ischemic limb. In the light of the literature and our experience, a patient with DKA should be considered at increased risk of thrombosis until proven otherwise and benefit from thromboprophylaxis from admission if there is no contraindication.

\section{Disclosure}

The authors declare that there are no conflicts of interest in this work.

\section{References}

1. Carr ME. Diabetes mellitus: a hypercoagulable state. J Diabetes Complications. 2001;15:44-54.

2. Hamblin PS, Topliss DJ, Chosich N, Lording DW, Stockigt JR. Deaths associated with diabetic ketoacidosis and hyperosmolar coma. 1973-1988. Med J Aust. 1989;151:41-42.

3. Buyukasik Y, Ileri NS, Haznedaroglu IC, et al. Enhanced subclinical coagulation activation during diabetic ketoacidosis. Diabetes Care. 1998;21:868-870.

4. Ileri NS, Buyukasik Y, Karaahmetoglu S, et al. Evaluation of the haemostatic system during ketoacidotic deterioration of diabetes mellitus. Haemostasis. 1999;29:318-325.
5. Bilici M, Tavil B, Dogru O, Davutoglu M, Bosnak M. Diabetic ketoasidosis is associated with prothrombotic tendency in children. Pediatr Hematol Oncol. 2011;28:418-424.

6. Carl GF, Hoffman WH, Passmore GG, et al. Diabetic ketoacidosis promotes a prothrombotic state. Endocr Res. 2003;29:73-82.

7. Worly JM, Fortenberry JD, Hansen I, Chambliss CR, Stockwell J. Deep venous thrombosis in children with diabetic ketoacidosis and femoral central venous catheters. Pediatrics. 2004;113:e57-e60.

8. Sdogou T, Kossiva L, Kakleas K, et al. Deep vein thrombosis and pulmonary embolism in a child with diabetic ketoacidosis and protein s deficiency: a case report. Horm Res Paediatr. 2013;79:114-118.

9. Alfred R, Wright-Pascoe R. Acute limb ischaemia in a septic patient with diabetic ketoacidosis. West Indian Med J. 2011;60:214-216.

10. Heit JA, Leibson CL, Ashrani AA, Petterson TM, Bailey KR, Melton LJ 3rd. Is diabetes mellitus an independent risk factor for venous thromboembolism?: a population-based case-control study. Arterioscler Thromb Vasc Biol. 2009;29:1399-1405.

11. Keenan CR, Murin S, White RH. High risk for venous thromboembolism in diabetics with hyperosmolar state: comparison with other acute medical illnesses. J Thromb Haemost. 2007;5:1185-1190.

12. Gutierrez JA, Bagatell R, Samson MP, Theodorou AA, Berg RA. Femoral central venous catheter-associated deep venous thrombosis in children with diabetic ketoacidosis. Crit Care Med. 2003;31:80-83.

13. Burzynski J. DKA and thrombosis. CMAJ. 2005;173:132. [author reply - 3]

14. Longmore JM. In: Wilkinson I, Baldwin A, Wallin E, editors. Oxford Handbook of Clinical Medicine. 9th ed. Oxford: Oxford University Press; 2014. 842-844.

15. Kian K, Eiger G. Anticoagulant therapy in hyperosmolar non-ketotic diabetic coma. Diabet Med. 2003;20:603.

16. Quigley RL, Curran RD, Stagl RD, Alexander JC Jr. Management of massive pulmonary thromboembolism complicating diabetic ketoacidosis. Ann Thorac Surg. 1994;57:1322-1324.

17. El Ghoussein H, Hegazi M, Alajmi M. Diabetic ketoacidosis presenting with saddle pulmonary embolism. Acta Endo (Buc). 2009;5:117-120.

18. Shujaat ASJ. Massive pulmonary embolism in diabetic ketoacidosis and non-ketotic hyperosmolar state: case series and review of the literature. Clin Intensive Care. 2004;15:73-77.

19. Jerjes-Sanchez C. Venous and arterial thrombosis: a continuous spectrum of the same disease? Eur Heart J. 2005;26(1):3-4.

20. Rumbaut RE, Thiagarajan P. Arterial, venous and microvascular hemostasis/thrombosis. Platelet-Vessel Wall Interactions in Hemostasis and Thrombosis. (Chap 6). San Rafael, CA: Morgan and Claypool Life Sciences; 2010. 35-42.

21. Lippi G, Franchini M, Targher G. Arterial thrombus formation in cardiovascular disease. Nat Rev Cardiol. 2011;8(9):502-512.

22. Kirchhof K, Welzel T, Mecke C, Zoubaa S, Sartor K. Differentiation of white, mixed, and red thrombi: value of CT in estimation of the prognosis of thrombolysis phantom study. Radiology. 2003;228(1):126-130.

23. Furlan AJ, Reisman M, Massaro J, et al; CLOSURE I Investigators. Closure or medical therapy for cryptogenic stroke with patent foramen ovale. N Engl J Med. 2012;366(11):991-999.

24. Meier B, Kalesan B, Mattle HP, et al; PC Trial Investigators. Percutaneous closure of patent foramen ovale in cryptogenic embolism. N Engl J Med. 2013;368(12):1083-1091.

25. Carroll JD, Saver JL, Thaler DE, et al; RESPECT Investigators. Closure of patent foramen ovale versus medical therapy after cryptogenic stroke. N Engl J Med. 2013;368(12):1092-1100. 
International Journal of General Medicine

Dovepress

\section{Publish your work in this journal}

The International Journal of General Medicine is an international, peer-reviewed open-access journal that focuses on general and internal medicine, pathogenesis, epidemiology, diagnosis, monitoring and treatment protocols. The journal is characterized by the rapid reporting of reviews, original research and clinical studies across all disease areas.
A key focus is the elucidation of disease processes and management protocols resulting in improved outcomes for the patient. The manuscript management system is completely online and includes a very quick and fair peer-review system. Visit http://www.dovepress.com/ testimonials.php to read real quotes from published authors.

Submit your manuscript here: http://www.dovepress.com/international-journal-of-general-medicine-journal 